\title{
Automatic Notching \& Drilling Machine
}

\author{
Ansari Mohammed Mazhar Mohammed Rashid, Khan Arshad Irfanullah, Khan Karim Jumma, \\ Mirajkar Danish Imtiyaz, Prof. Ameya Nadkarni \\ Dept. of Mechanical Engineering, Rizvi College of Engineering, \\ Bandra (W), Mumbai
}

\begin{abstract}
Notching, Punching and Drilling Machine is a tedious task and requires a lot of human effort. Punching and drilling multiple sheets at a time requires a lot of energy as well as time when done manually. However, it has to be done anyways because it is the basic operations for a lot of manufacturing process and many production companies uses these operations. So here we propose an Automated Notching, Punching and Drilling Machine that uses motorized sheet Notching, punching and drilling system for fast, continuous, automatic and perfect notching, punching and drilling with minimum manual efforts. The important components of our project are, Geneva \& Slider Crank Mechanism, Drive (Motor), Power supply, Conveyor Rolls, Sprocket \& Chain, Operating Tool. Our system makes use of motor that drives the Geneva mechanism and the slider crank mechanism in combination. The Slider in the slider crank mechanism is made as the tool holder to which the tool is attached and is the operation-performing end of the mechanism. While the Geneva mechanism rotates $1 / 4$ times the actual rotation of the motor and a sprocket is attached to its other end. This sprocket drives the conveyor rollers through the sprocket and chain arrangement on the rear side of the frame. Thus, a single motor and only using the mechanical means operate the operation as well as the conveyor. Thus, we save a lot of time and efforts by automating the processes. Any type of operation can be performed along with the conveyor movement using this machine design just by changing the operating tool at the slider end.

Performable Operations: Notching, Punching, Drilling, Blanking, Lancing etc.
\end{abstract}

Key Words: Automated, Fast \& Continuous, Geneva \& Slider Crank Mechanism, Multiple Operations.

\section{INTRODUCTION}

Due to increase in industrialization, there is huge development in the field of manufacturing which requires modernization of manufacturing machine and increase demand of product in the market requires large production setup. However, due to shortage of place in the urban cities the manufacturing machine should be compact in size so that it can be installed in small place.

These are following necessities:-

- To achieve the higher productivity and quality operations.

- To reduce the excess machinery and labour hours.

- To achieve the continuous flow of apparel production

- To reduce the cost of the operation.

- To perform number of operation in one machine which will indirectly save time of production.

- To reduce the space required for installation.

\section{FUNCTIONS}

Automatic Notching \& Drilling Machine provides many useful functions:
- The function is to Notch number of hole in a piece of work simultaneously and to reproduce the same pattern of holes in number of identical pieces in a mass production

- Apart from notching a number of other machining operations like Punching, Drilling, Blanking, Lancing, Embossing etc. can also be performed by changing the slider tool holder on this machine.

- It can be used for drilling long workpiece in continuous manner and at different interval by adjusting the speed and torque supplied by the motor and the ratio of sprockets.

- The machine performs the tooling operation as well as the conveyor movement simultaneously using a single motor.

\section{WORKING}

When the switch is turned ON the power supply will supply power to the DC motor. The power supply takes the input of $230 \mathrm{~V}$ AC current and converts in to give output of $12 \mathrm{~V} \mathrm{DC}$ 5Amp. The motor then starts rotating on 90rpm at the given power and this rotation motion of the motor is given to the Crank wheel. From the crank wheel the power is distributed in two directions i.e. the two mechanisms Slider Crank Mechanism and the Geneva mechanism.

Slider Crank Mechanism: Here the circular motion of the crank is transferred into the reciprocating motion of the sliding piston. The slider part in our mechanism is the sliding tool holder to which the tool is attached. Here the motion is used to perform the working operation such as notching, piercing or drilling operation etc.

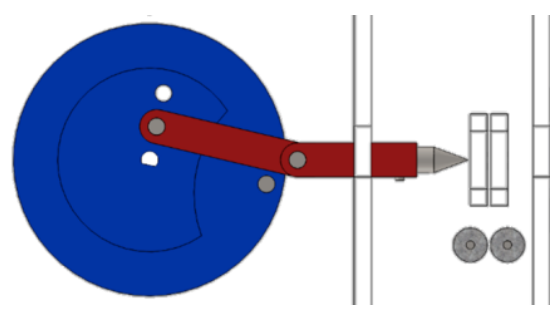

Fig. Slider Crank Mechanism 
Geneva Mechanism: Here the motion is transferred from the crank to the Geneva wheel through the Geneva pin. The Geneva wheel takes $1 / 4$ rotation on every one rotation of the crank wheel, this $1 / 4$ rotation is used to power the conveyor rolls through the sprocket and

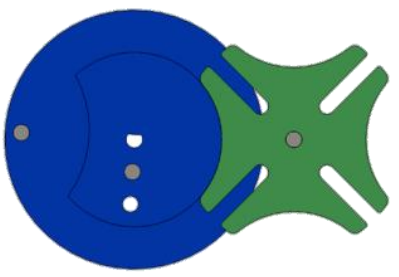

Fig. Geneva Mechanism chain mechanism.

The mechanism is so arranged that when the operation at the productive end is done at that time the conveyor rolls are stationary and they only moves when the operation at the working end of the machine is done and the tool is at the farthest position.

So when the crank wheel starts to rotate first the slider crank mechanism is operated performing the working operation and when the operation is performed and the tool is away from the workpiece then the Geneva mechanism is operated which operates the conveyor rolls and the workpiece is moved ahead and a new section of the workpiece is placed at the operating station i.e. near the tool and then again the slider crank operation is performed which produces the working operation at the working end. Hence, the cycle keep on going and gives a continuous production without any human interference thereafter and the operations are done completely automatic.

- The distance between the points on the workpiece where the operation is performed can be varied by varying the ratio of the sprockets that connects the conveyor rolls to the Geneva wheel.

- The travel movement of the sliding tool holder can be varied by using the different holes on the crank wheel as the hinge point of the crank wheel and the connecting rod.

\section{OPERATIONS THAT CAN BE PERFORMED}

Multiple sheet cutting operations can be performed on the on our machine. In cutting operations the sheet metal is stressed beyond its ultimate strength whereas in forming operations the stresses are below the ultimate strength of the metal.

In sheet metal operations the metal is sheared hence also called as shearing operations. In this operation the metal sheet is stretched beyond its ultimate strength. They include following operations: - Notching, Drilling, Punching, Piercing, Blanking, Lancing, Nibbing etc.

\section{SAFETY}

Safety plays a key role in keeping a construction project on schedule and on budget. Success on any construction project depends on keeping it on time and on budget. The focused planning and performance necessary to ensure that a project is completed safely are crucial in keeping it on schedule and on budget.

In our project the operation is performed in a completely automated manner and hence there is least involvement of human workers which states that the project is highly safe in operation. The human involvement is only seen while starting the operation and ending of the operation. Moreover the operations performed in the project is totally covered while the project is $\mathrm{ON}$ and in working condition, this showsthat there are very less chance of any kind of accident to happen on the workshop due to the project. And while the machine is in the working condition there is no worker interference in the process except for observing the project for any kind of errors.

\section{COMPLETE PROJECT MECHANISM}

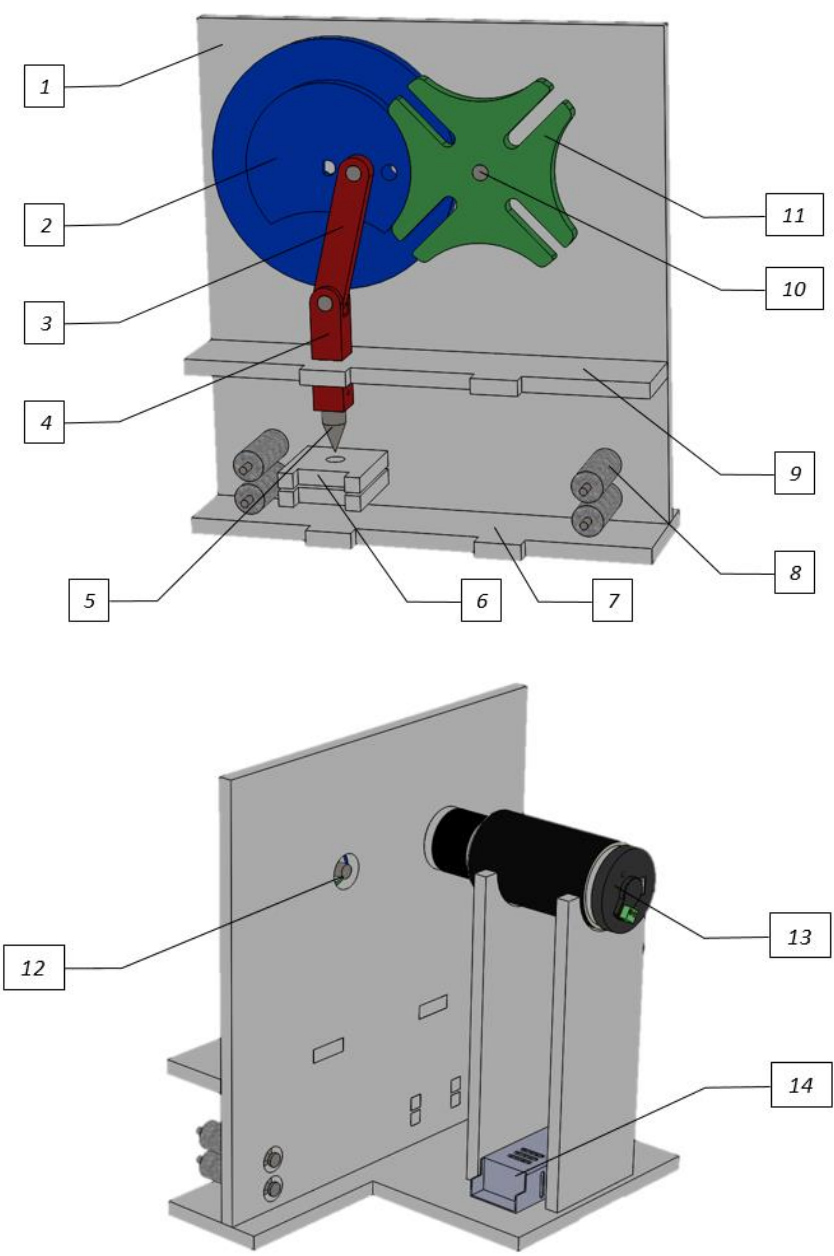

\begin{tabular}{|c|c|c|c|}
\hline Part No. & Part Name & Part No. & Part Name \\
\hline 1 & Main Frame & 8 & Conveyor Rolls \\
\hline 2 & Crank Wheel & 9 & Vertical Cover \\
\hline 3 & Connecting Rod & 10 & Pin \\
\hline 4 & Sliding Tool Holder & 11 & Geneva Wheel \\
\hline 5 & Tool & 12 & Bearing \\
\hline 6 & Tool Guide & 13 & Motor \\
\hline 7 & Frame Base & 14 & Power Supply \\
\hline
\end{tabular}

\section{PROJECT COMPONENTS}

1. Sliding Tool Holder:-This part acts as the slider of the sliding crank mechanism as well as the tool holder at the same time. The upper portion of the part is attached to the connecting rod through a hinged join and at the lower part there is provision for the tool to be inserted. The tool is held over here by inserting a pin through the tool. 


\section{Tool:-}

This machine can be used for multiple operations as stated before such as Notching, Punching and Drilling etc. The only thing to be changed is the tool. By using the specific tool we can perform no. of operations on the given machine. The tool currently attached to the machine is a Piercing tool that creates circular marks on the workpiece. The tool is made up of High Grade M.S. material and the dimensions of the tool are: Overall Length $=50 \mathrm{~mm}$, Tool Dia. $=10 \mathrm{~mm}$, Shank $=30 \mathrm{~mm}$, Taper angle $=14^{\circ}$.

\section{Conveyor Rolls:-}

The conveyor rolls are made up of transparent acrylic material. The acrylic rolls of $20 \mathrm{~mm}$ dia. are first cutted into length of $50 \mathrm{~mm}$ and then a $7 \mathrm{~mm}$ dia. hole is drilled in the center on lathe machine for accurate center. $7 \mathrm{~mm}$ dia. steel pins are then incorporated in these holes and the remaining $10 \mathrm{~mm}$ pin on both the side is supported in the bearings on the frame. These conveyor rolls are used to move the raw material while the machine is in working condition. These are operated by the Geneva mechanism through the chain and sprocket arrangement.

\section{BCI Motor - BCI 52.60 PX Planetary gearbox - 24V} DC:-

DC motor with planetary gearbox PX 42 and PX 52. Robust zinc die cast housing in modular construction. Grease lubrication for maintenance free operation.

\section{Power Supply:-}

Input: $230 \mathrm{AC} 50 \mathrm{~Hz}$

Output: 12V DC 5A

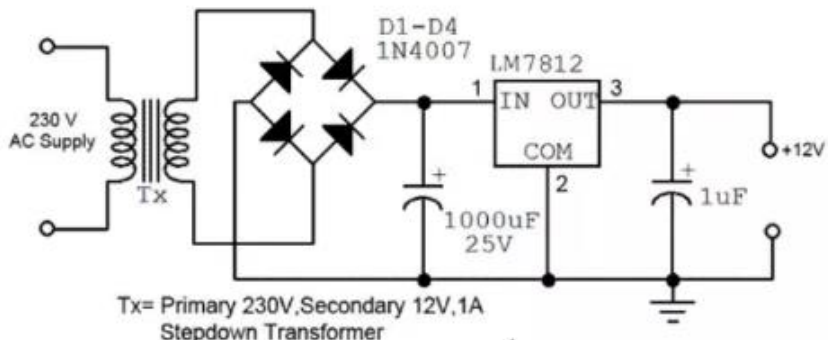

6. Chain \& Sprocket:-

Maximum Center to Center Distance Available $=204 \mathrm{~mm}$

Calculated Chain length $=234 \mathrm{~mm}$

With FOS: 7.8

Pitch Dia. of Sprocket 1:- $35 \mathrm{~mm}$

Pitch Dia. of Sprocket 2:- 40mm
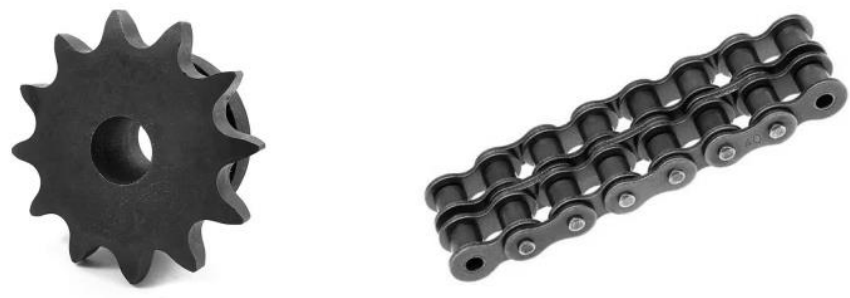

\section{Pin \& Bearing:-}

Pin of dia. $10 \mathrm{~mm} \mathrm{\&} 7 \mathrm{~mm}$ in length of $20,30 \& 70 \mathrm{~mm}$ made of High Grade Steel are used after calculating the safe load.
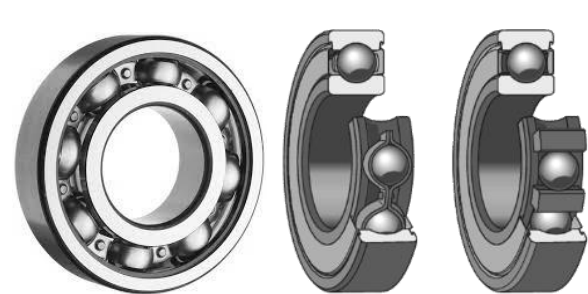

Bearings that are considering the application, speed, environment and size of the project are of 6000 Series \& 6201 Series.

VIII. MANUFACTURING PROCESS

A. Designing of Project

Software: Solid Work, Ansys, Corel Draw.

\begin{tabular}{|c|c|c|}
\hline $\begin{array}{l}\text { Sr. } \\
\text { No. }\end{array}$ & Description Of Operation & $\begin{array}{l}\text { Software } \\
\text { Used }\end{array}$ \\
\hline 1 & $\begin{array}{l}\text { Creating a basic model of the project on paper } \\
\text { to get an idea of the project model. }\end{array}$ & $N A$ \\
\hline 2 & Confirming the model with the guide. & $N A$ \\
\hline 3 & $\begin{array}{c}\text { Creating the model parts with approximate } \\
\text { dimensions and assembling to work as a } \\
\text { working model. }\end{array}$ & SolidWorks \\
\hline 4 & $\begin{array}{l}\text { Giving suitable material to the parts and } \\
\text { checking for failure by applying the load. }\end{array}$ & Ansys \\
\hline 5 & $\begin{array}{l}\text { Optimizing the dimensions and finalizing the } \\
\text { material from the analysis. }\end{array}$ & $\begin{array}{l}\text { SolidWorks } \\
\text { Ansys }\end{array}$ \\
\hline 6 & $\begin{array}{l}\text { Making the layout of the parts to be laser cut in } \\
\text { a way that it occupy the least space to reduce } \\
\text { scrap. }\end{array}$ & Corel Draw \\
\hline
\end{tabular}

\section{B. Laser Cutting:-}

Laser cutting is a technology that uses a laser to slice materials. While typically used for industrial manufacturing applications, it is also starting to be used by schools, small businesses, and hobbyists. Laser cutting works by directing the output of a high-power laser most commonly through optics. The laser optics and $\mathrm{CNC}$ (computer numerical control) are used to direct the material or the laser beam generated. A commercial laser for cutting materials uses a motion control system to follow a CNC or G-code of the pattern to be cut onto the material. The focused laser beam is directed at the material, which then either melts, burns, vaporizes away, or is blown away by a jet of gas, leaving an edge with a high-quality surface finish.

\section{Vaporization cutting:-}

In vaporization cutting the focused beam heats the surface of the material to boiling point and generates a keyhole. The keyhole leads to a sudden increase in absorptivity quickly deepening the hole. As the hole deepens and the material boils, vapor generated erodes the molten walls blowing ejecta out and further enlarging the hole. Non melting material such as wood, carbon and thermoset plastics are usually cut by this method. 


\section{Manufacturing of Project}

Material: Anti-Static Black Colored High Grade Acrylic Sheet

\begin{tabular}{|c|c|c|}
\hline Sr. No. & Description Of Operation & Method Used \\
\hline 1 & $\begin{array}{c}\text { Making the layout of the parts to be } \\
\text { laser cut in a way that it occupy the } \\
\text { least space to reduce scrap. } \\
\text { (Layout Attached) }\end{array}$ & Corel Draw \\
\hline 2 & $\begin{array}{c}\text { Laser cutting the layout on a 2x2 Sq. } \\
\text { ft. Acrylic sheet. }\end{array}$ & $\begin{array}{c}\text { Laser Cutting } \\
\text { Machine }\end{array}$ \\
\hline 3 & $\begin{array}{c}\text { Precisely removing the parts from the } \\
\text { laser cutted sheet }\end{array}$ & Manually \\
\hline 4 & $\begin{array}{c}\text { Sticking different parts together from } \\
\text { the laser cutted sheet to form a single } \\
\text { part e.g. tool holder, Geneva wheel, } \\
\text { etc. }\end{array}$ & $\begin{array}{c}\text { Adhesive such as } \\
\text { feviquick \& } \\
\text { Araldite }\end{array}$ \\
\hline 5 & $\begin{array}{c}\text { Marking different points on the laser } \\
\text { cutted parts that is to be machined i.e. } \\
\text { Drilling, Boring, etc. }\end{array}$ & $\begin{array}{c}\text { Hand Punch \& } \\
\text { Marker }\end{array}$ \\
\hline 6 & $\begin{array}{c}\text { Performing the machining operation } \\
\text { on the marked points }\end{array}$ & $\begin{array}{c}\text { Marious } \\
\text { Mafacturing } \\
\text { Machines }\end{array}$ \\
\hline 7 & $\begin{array}{c}\text { Assembling the parts and tools using } \\
\text { screws and adhesives to complete the } \\
\text { machine assembly }\end{array}$ & Manually \\
\hline
\end{tabular}

\section{OBJECTIVES}

- To increase the production.

- To reduce the time for handling.

- To reduce the work load on operator.

- To increase the compactness and flexibility of the operation.

- It can be used for performing different operations on different materials.

- It can be used to perform operation in small scale and large scale industries for increasing production rates.

- It is very cheap and can be installed at any place.

- Operation can be carried out with minimum expenditure.

\section{FUTURE SCOPE}

- The machine can be made more advanced automated by using software technologies, controllers, etc.

- The machine can be made hydraulically power operated by installing the gear oil pump at the place of motor

- The place where there is scarcity of the electricity the electric motor that operates the Geneva can be replaced by the I.C. Engine.

- This multipurpose machine can be modified into universal machine

- If the slots in the Geneva wheel are increased the number of punched holes can also be increased without any additional efforts.

- Large scale production and implementation in industry can be done

\section{REFERENCES}

[1] Georgeta Haraga, Elena IONITA, Ana-Maria AVRAMESCU (2012) "Anaylisis and Modeling of Geneva Mechanism", The paper presents some aspects theoretical and practical based on the finite element analysis and modelling of Geneva mechanism with four slots. We used this analysis of and designed the Geneva .As per our application we needed light weight material for our project. So with these analysis we determine forces acting on it and also weaker sections of Geneva.

[2] Sudeep Kelaginamane, Sridhar D. R. (2015), "PLC Based Pneumatic Punching Machine", The work here describes about the design and fabrication of automatic sheet metal punching machine controlled by Programmable Logic Controller (PLC). As we needed to perform the Operation of Punching.The force acting on the tool and Geneva need to be calculated also in our project for punching Operation we added die so that workpiece is properly made.With the help of this project we change the Operation of Punching with Geneva instead of PLC

[3] Jih Lian Ha, Rong-Fong Fung, Kun-Yung Chen, Shao-Chein Hsein (2005) "Dynamic Modeling and Identification of a Slider Crank Mechanism", In this paper, Hamilton's principle, Lagrange multiplier geometric constraints and partitioning method are employed to derive the dynamic equations of a slider-crank mechanism driven by a servomotor.As we needed the motion for the tool we used this journal paper.At one end of the crank was Geneva and other was connected to the tool and we provided a intermittent motion to the tool.

[4] P. Ramesh, T. Abhinesh, R. Aravind Babu, P.R. Jagadesh Babu (2019): In this paper the description is given about chain and sprockets.We needed a motion for raw material so we used chain and sprocket .One Sprocket would provide the motion for the tool and second one provided for raw material.Hence a motor would fulfill the both criteria and which result in loss of power.Also we checked for Sprockets whether proper transmission of power is done.

\section{ACTUAL PHOTOS OF PROJECT}
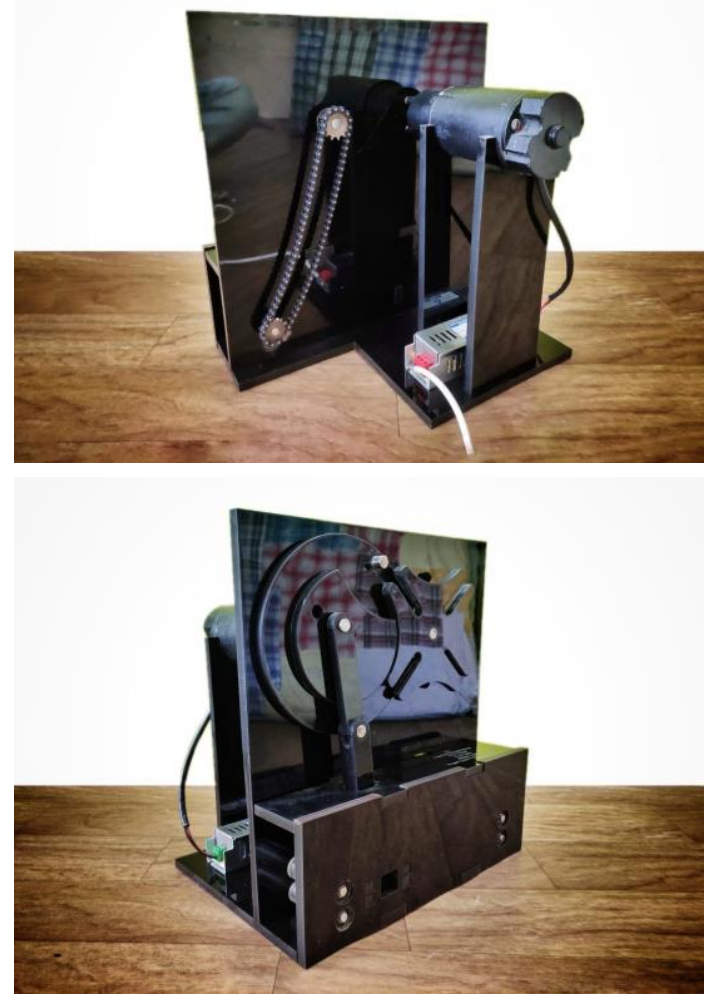